This survey gathers health information before your check-up and will be used as a reference during consultation. Confidentiality is guaranteed. Please be sure to answer all questions candidly and sincerely to help protect and improve your health. Please fill in the questions by yourself. If you need help, consult a parent or guardian.

1. This is a question about ENT disease.

\begin{tabular}{|l|c|c|}
\hline \multicolumn{1}{|c|}{ Disease } & $\begin{array}{c}\text { Has been diagnosed } \\
\text { by a doctor (lifetime) }\end{array}$ & $\begin{array}{c}\text { Treatment during } \\
\text { the last 2 weeks } \\
\text { (surgery, medication, etc.) }\end{array}$ \\
\hline Rhinosinusitis & $\square$ Yes $\square$ No & $\square$ Yes $\square$ No \\
\hline Ear infection & $\square$ Yes $\square$ No & $\square$ Yes $\square$ No \\
\hline 2. Choose the sentence that best describes your hearing. \\
\hline \multicolumn{2}{|c|}{ Item } & Select \\
\hline No problem $\Rightarrow$ Go to question no. 4. & $\square$ \\
\hline Somewhat uncomfortable & $\square$ \\
\hline Very uncomfortable & $\square$ \\
\hline I can't hear at all. & $\square$ \\
\hline 3. Are you currently using a hearing aid or cochlear implant? \\
\hline \multicolumn{2}{|c|}{ Item } & Select \\
\hline Yes & $\square$ \\
\hline Ihave one but rarely use it & $\square$ \\
\hline No & $\square$ \\
\hline
\end{tabular}

4. Have you ever heard a sound in your ear in the past year? (a low buzzing, buzzing, humming, or machine-like sound, etc.)

\begin{tabular}{|c|c|}
\hline buzzing, buzzing, humming, or machine-like sound, etc.) \\
\hline Item & Select \\
\hline
\end{tabular}

\begin{tabular}{|l|c|}
\hline Yes & $\square$ \\
\hline No $\Rightarrow$ Go to question no. 6 & $\square$ \\
\hline Idon't rememer $\Rightarrow$ Go to question no. 6 & $\square$ \\
\hline
\end{tabular}

I don't remember $\Rightarrow$ Go to question no. 6

5. How uncomfortable does the sound in your ear make you?

\begin{tabular}{|c|c|}
\hline 5. How uncomfortable does the sound in your ear make you? \\
\hline Item & Select \\
\hline
\end{tabular}

\section{No problem}

I am annoyed and bothered

I find it hard to sleep.

6. The following questions are about your use of earphones and headphones. Please answer the questions.

\begin{tabular}{c} 
headphones. Please answer the questions. \\
\hline Items \\
\hline
\end{tabular}

Do you use any portable music or video Yes

playback device such as a smartphone, $\square$ No $\Rightarrow$ Go to question no. 7

MP3 player, a PMP, etc?

When did you start using it? Years of age

\begin{tabular}{|l|l}
\hline What device do you usually use? & ¿Earphones $₫$ Headphones
\end{tabular}

Has anyone nearby ever asked you to

turn down the volume when you were $₫$ Yes $₫$ No

using a portable playback device?

What volume level do you set when using a portable music player?

$\begin{array}{lllllllllll}0 & 1 & 2 & 3 & 4 & 5 & 6 & 7 & 8 & 9 & 10\end{array}$

\section{Questionnaire}

(for middle/high school students)

7. Please describe your experience with the following equipment or facilities during the past year.

\begin{tabular}{|c|c|c|c|c|}
\hline Item & $\begin{array}{c}\text { Experienced } \\
\text { or not }\end{array}$ & $\begin{array}{l}\text { Age at first } \\
\text { use }\end{array}$ & $\begin{array}{c}\text { Frequency of } \\
\text { use }\end{array}$ & $\begin{array}{c}\text { Average time } \\
\text { spent on each } \\
\text { visit }\end{array}$ \\
\hline & & & & \\
\hline $\begin{array}{l}\text { LAN } \\
\text { gaming } \\
\text { center }\end{array}$ & $\square$ & years old & times/month & _ hours \\
\hline Karaoke & $\square$ & $\overline{\text { years old }}$ & times/month & __ hours \\
\hline Concert & 口 & years old & times/month & _ \\
\hline $\begin{array}{c}\text { Club, } \\
\text { discotheque }\end{array}$ & 口 & years old & times/month & _ \\
\hline
\end{tabular}

8. Please fill out the location of your seat in class for the past 3 years, and explain why you are in that seat.

\begin{tabular}{|c|c|c|c|c|c|c|c|}
\hline & \multicolumn{3}{|c|}{ Based on } & \multirow{2}{*}{\multicolumn{4}{|c|}{ Distance from lecture podium }} \\
\hline & Height & Grade & Choice & & & & \\
\hline $\begin{array}{c}1 \text { year } \\
\text { ago }\end{array}$ & 口 & 口 & 口 & Very close Close & Middle & Far & Very far \\
\hline $\begin{array}{c}2 \text { years } \\
\text { ago }\end{array}$ & $\square$ & $\square$ & $\square$ & Very close Close & Middle & Far & \\
\hline $\begin{array}{c}3 \text { years } \\
\text { ago }\end{array}$ & $\square$ & $\square$ & 口 & Very close Close & & Far & Very far \\
\hline
\end{tabular}

9. Please rate your grades for the past three years.

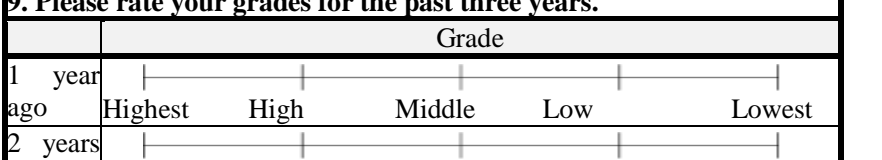
\begin{tabular}{|l|lllll} 
ago & Highest & High & Middle & Low & Lowest \\
\hline 2 years & $!$ & $\mid$ & $\mid$ & & $\mid$ \\
Highest & High & Middle & Low & Lowest
\end{tabular} \begin{tabular}{l|lllll} 
go & Highest & High & Middle & Low & Lowest \\
years & $\longmapsto$ & $\mid$ & $\mid$ & &
\end{tabular} ago Highest High Middle Low Lowest 10. The following questions explore your smoking-related behavior. 1) Have you ever smoked a cigarette, including just one or two puffs? $\square$ Never so far $\Rightarrow$ Go to question no. 11

$\square$ Yes

2) When was the first time you smoked a cigarette, including just one or two puffs?

3) On how many days did you smoke cigarettes during the last month? days

$\square$ Have not smoked during the last month $\Rightarrow$ Go to question no. 1

4) How many cigarettes did you smoke daily (on average) during the la 4) How
month?

Average

cigarettes

\begin{tabular}{|l|l|l|l|}
\hline \multirow{3}{*}{$\begin{array}{l}\text { Student's } \\
\text { personal } \\
\text { information }\end{array}$} & School name & school & \\
\cline { 2 - 4 } & Grade/Class & grade & class \\
\cline { 2 - 4 } & Recipient Code & \multicolumn{3}{|c|}{} \\
\cline { 2 - 4 } & Gender & Male & Female \\
\hline
\end{tabular}

11. The following questions explore your drinking-related behavior.

1) Have you ever drunk more than one drink?

※ Excepting a sip or two during memorial services

$\square$ Have never drunk $\Rightarrow$ Go to question no.13

$\square$ Yes

When was the first time you drank a whole cup of alcohol? * Excepting a sip or two during memorial services years of age

12. The following questions explore your drinking experience during the past year.

1) How often do you drink alcohol?

Did not drink at all for the past year $\Rightarrow$ Go to question no. 13 Less than once a month

About once a month

2-4 times a month

2-3 times a week

More than 4 times a week

How many drinks do you consume at one time?

* Each drink of liquor is counted regardless of alcohol type One can of beer $(355 \mathrm{~mL})$ is equivalent to 1.6 cups of beer

1-2 cups

3-4 cups

5-6 cups

7-9 cups

More than 10 cups

13. What is your current height $(\mathrm{cm})$ and weight $(\mathrm{kg})$ ?

\begin{tabular}{|l|l|}
\hline 1. Height $(\mathrm{cm})$ & 2. Weight $(\mathrm{kg})$ \\
\hline & \\
\hline
\end{tabular}




\begin{tabular}{|c|c|c|c|c|c|}
\hline \multicolumn{6}{|c|}{$\begin{array}{l}\text { This survey gathers health information before your check-up and will be } \\
\text { used as a reference during consultation. Confidentiality is guaranteed. } \\
\text { Please be sure to answer all questions candidly and sincerely to help } \\
\text { protect and improve your health. Please fill in the questions by yourself. If } \\
\text { you need help, consult a parent or guardian. }\end{array}$} \\
\hline \multicolumn{6}{|c|}{$\begin{array}{l}\text { 1. If any of your family members have ever been treated or diagnosed } \\
\text { with the following diseases, please mark "V". }\end{array}$} \\
\hline \multirow{2}{*}{\multicolumn{2}{|c|}{\begin{tabular}{|l|} 
Family medical history \\
Hypertension or cerebral stroke (stroke)
\end{tabular}}} & Yes & Who & $\mathrm{Nan}$ & e of disease \\
\hline & & & & & \\
\hline \multicolumn{2}{|c|}{$\begin{array}{l}\text { Heart diseases such as angina, } \\
\text { myocardial infarction, and/or hear } \\
\text { failure }\end{array}$} & & & & \\
\hline \multicolumn{2}{|c|}{ Diabetes } & & & & \\
\hline \multicolumn{2}{|l|}{ Cancer } & & & & \\
\hline \multicolumn{2}{|l|}{ Liver disease } & & & & \\
\hline \multicolumn{2}{|c|}{ Tuberculosis } & & & & \\
\hline \multicolumn{2}{|c|}{ A psychiatric disorder } & & & & \\
\hline \multicolumn{6}{|c|}{$\begin{array}{l}\text { 2. If you have had any of the following diseases during the past year } \\
\text { please mark "V" and write down the specific disease name. }\end{array}$} \\
\hline \multicolumn{4}{|c|}{ Medical history } & Yes & $\begin{array}{c}\text { Name of } \\
\text { disease }\end{array}$ \\
\hline \multirow{3}{*}{$\begin{array}{l}\text { Digestive } \\
\text { system }\end{array}$} & \multicolumn{3}{|l|}{ Gastritis or peptic ulcer } & & \\
\hline & \multicolumn{3}{|l|}{ Constipation } & & \\
\hline & \multicolumn{3}{|l|}{ Enteritis } & & \\
\hline \multirow{4}{*}{$\begin{array}{l}\text { Respiratory } \\
\text { system }\end{array}$} & \multicolumn{3}{|l|}{ Asthma } & & \\
\hline & \multicolumn{3}{|l|}{ Sinusitis } & & \\
\hline & \multicolumn{3}{|c|}{ Allergic rhinitis or chronic rhinitis } & & \\
\hline & \multicolumn{3}{|c|}{ Tonsillar hypertrophy } & & \\
\hline \multicolumn{4}{|c|}{$\begin{array}{ll}\text { Fye } & \text { Eye disease, strabismus, etc. }\end{array}$} & & \\
\hline \multirow{2}{*}{$\begin{array}{cl}\text { Eye } \\
\end{array}$} & & & \\
\hline & \multicolumn{3}{|l|}{ Hearing impairment } & & \\
\hline & Other ear diseases (tinnitus, e & & & & \\
\hline & Atopic dermatosis & & & & \\
\hline SKIn & Other skin diseases & & & & \\
\hline Circulatory & Anemia & & & & \\
\hline system & Hypertension & & & & \\
\hline & Scoliosis & & & & \\
\hline $\begin{array}{c}\text { Musculo- } \\
\text { skeletal }\end{array}$ & Disk or back pain & & & & \\
\hline $\begin{array}{l}\text { Skeletal } \\
\text { system }\end{array}$ & Disorder of limb movement & & & & \\
\hline & Injury or accident & & & & \\
\hline & Pediatric psychiatric disorder & & & & \\
\hline & Tuberculosis & & & & \\
\hline & Drug allergy & & & & \\
\hline & Diabetes & & & & \\
\hline & Headache (except migraine) & & & & \\
\hline & Convulsion or seizures (spasn & & & & \\
\hline diseases & Speech disorder (including stut & tering) & & & \\
\hline & Hepatitis (from childhood) & & & & \\
\hline & Surgical experience (from child & hood) & & & \\
\hline & $\begin{array}{lr}\begin{array}{l}\text { Hospitalization } \\
\text { childhood) }\end{array} & \text { experienc } \\
\end{array}$ & & & & \\
\hline & $\begin{array}{l}\text { Other diseases (addiction, su } \\
\text { etc.) }\end{array}$ & & & & \\
\hline
\end{tabular}

\section{Questionnaire}

\section{(for middle/high school students)}

3. Please mark "V" for all the symptoms you have experienced in the past month.

\begin{tabular}{|c|c|c|c|}
\hline Item & Symptoms & Yes & No \\
\hline
\end{tabular}

\begin{tabular}{l|l}
\multirow{3}{*}{ Condition } & Catch colds easily. \\
\cline { 2 - 2 } & I lack strength and I get tired easily. \\
\hline
\end{tabular} I think I am not healthy.

My nose and eyes are itchy, I sneeze, an sometimes I have a clear runny nose.

I experience shortness of breath and I hear whistles from my chest.

I have yellow sputum when I cough

I usually have trouble breathing through my nose because my nose is blocked.

I am told that I often snore badly. I often have fever and a sore throat. There is a lump in my neck.

I get out of breath, even with little exercise compared with others.

Circulatory My complexion is bad and my heart pounds even when I am at rest.

I have a burning feeling or pain in my stomach. Digestive I feel stuffy or full.

system My lower belly is painful or I often have diarrhea.

My stomach feels tight or bloated. I feel hopeless because I am sad or depressed. I often do not want to go to school.

I have seriously considered suicide or attempted

suicide.

often feel nervous as if I am going crazy.
un

often feel nervous as if I am going crazy.
I am not calm. I am too active, which car I am not calm. I am too active, which
interfere with the activities of other children. interfere with the activities of other children.

Blood not stop quickly if I am injured I get bruised easily.

My headache or migraine is severe. My ears are sore or I have an ear discharge. I hear buzzing in my ear.

Other My jaw joints are sore or I cannot open \begin{tabular}{c|c} 
Other \\
symptoms
\end{tabular} My jaw jointh well. I have a throbbing pain in my neck/waist/knee etc. (For girls) My menstrual cramps are severe.

Anything you want

to say to you

doctor?

\begin{tabular}{|c|c|c|c|}
\hline \multirow{3}{*}{$\begin{array}{c}\text { Student's personal } \\
\text { information }\end{array}$} & School name & \multicolumn{2}{c|}{ school } \\
\cline { 2 - 4 } & Grade/ Class & \multicolumn{2}{|c}{ grade } \\
\cline { 2 - 4 } & Recipient Code & & \\
\cline { 2 - 4 } & Gender & Male & Female \\
\hline
\end{tabular}

4. The following questions are about your health-related behavior

\begin{tabular}{|c} 
Please use "V" to answer. \\
\hline Healthy lifestyle \\
\hline
\end{tabular}

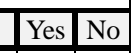

I eat breakfast regularly.

I drink milk or dairy products every day

I eat vegetables and fruits every day

Diet I rarely eat sweet or salty food.

I consume soft drinks, hamburgers, pizza, o snacks almost every day.

I skip meals or take drugs to lose weight.

Personal I wash my hands with soap before eating or aft

Personal going out.

I brush my teeth more than twice a day.

I exercise intensely at least three times a week.

Exercise I allocate study and exercise time well. I feet refreshed after sleeping.

I wear a seat belt when I ride in a car.

Safety I wear a helmet or protective gear when I use inlin skates, roller blades, skateboards, bicycles, etc Internet a day.

I often watch pornography or chat on adult sites.

I have been bullied or isolated by my friends over the past year.

I have a person to talk to when I have worries o problems.

Home \& I am worried about problems in my family.

school life I have seriously considered running away from I have seriously considered
home during the past year.

My safety is threatened by violence at home school.

I have carried a knife/club/nunchaku as a weapon. I have smoked during the past month.

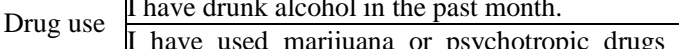
hallucinate. I worry about gender issues.

Sexuality I have been abused physically, mentally, and/o sexually.

I'd like to receive consultation on my worries an roublesome matters.

At school's discretion)

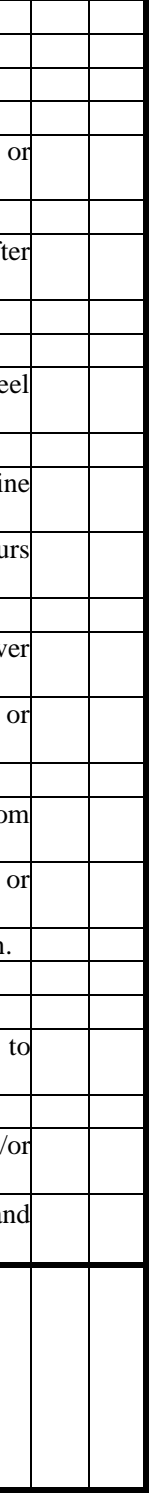


이 설문조사는 건강검사에 앞서 여러분의 건강상태를 미리 알아보고 진찰을 받을 매 참고하기 위한 것입니다. 비밀이 보장되므로 설문내용에 솔직하고 성실하게 답변해서 여러분 자신의 건강보호 및 향상에 도움이 되도록 합시다. 본인이 작성하되 잘 모르는 문항은 부모님(보호자)과 상의하여 기재하기 바랍니다.

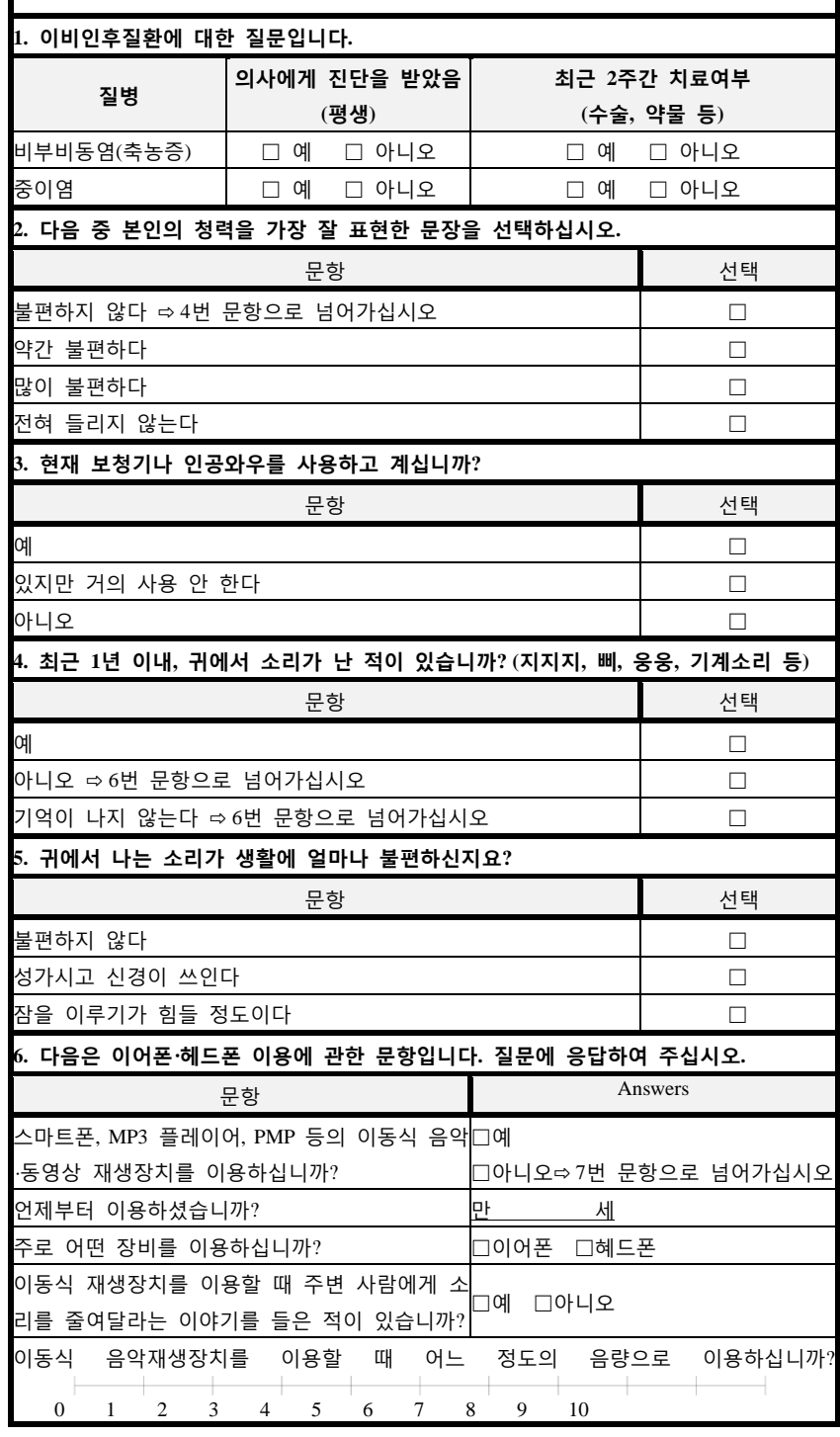

문 진 표

(중·고등학생용)

7. 최근 1 년 동안의 다음의 기기 또는 시설을 이용한 경험에 대하여 기입하여 주십시

\begin{tabular}{|c|c|c|c|c|c|}
\hline \multicolumn{2}{|c|}{ 항목 } & 이용여부 & 최초 이용 시기 & 이용 빈도 & 1 회 평균 시간 \\
\hline \multicolumn{2}{|c|}{ PC 방 } & $\square$ & 만_세 & 월_—회 & _ 시간 \\
\hline \multicolumn{2}{|c|}{ 노래방 } & $\square$ & 만__세 & 월 & —시간 \\
\hline \multicolumn{2}{|c|}{ 콘서트장 } & $\square$ & 만__세 & 연간___회 & —시간 \\
\hline \multicolumn{2}{|c|}{ 클럽, 디스코텍 } & $\square$ & 만_세 & 연간__ & 시간 \\
\hline \multicolumn{6}{|c|}{ 3. 지난 3년간 학생의 좌석의 위치와 좌석의 기준을 기입하여 주십시오. } \\
\hline & \multicolumn{2}{|c|}{ 기준 } & \multirow{2}{*}{\multicolumn{3}{|c|}{ 교탁과의 거리 }} \\
\hline & 키 & 성적 자율 & & & \\
\hline 1년 전 & $\square$ & $\square$ & 매우 가깝다가깝다 & 중간쯤이다 멀드 & 매우 멀다 \\
\hline 2년 전 & $\square$ & $\square$ & 매우 가깝다가깝다 & 중간쯤이다 멀다 & 매우 멀다 \\
\hline 3년 전 & $\square$ & $\square$ & 매우 가깝다가끕 & 중간쯤이다 멀다 & 매우 멀다 \\
\hline
\end{tabular}

9. 지난 3 년간 학생의 학급 내 성적을 체크하여 주십시오.

\begin{tabular}{|c|c|c|c|c|c|}
\hline & \multicolumn{5}{|c|}{ 성적 } \\
\hline 1년 전 & 다기기 & & & & \\
\hline 2년 저 & 1 & 1 & & & \\
\hline & 최상위권 & 상위권 & 중위권 & 하위권 & 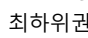 \\
\hline 3년 전 & $P$ & 1 & & & \\
\hline & 최상위권 & 상위권 & 중위권 & 하위권 & 최하위권 \\
\hline
\end{tabular}

\section{0. 다음은 여러분의 흡연과 관련된 행동에 대한 질문입니다.}

1) 지금까지 담배를 한 두 모금이라도 피워 본 적이 있습니까?

지금까지 없음 $\Rightarrow 11$ 번 문항으로 넘어가십시오

$\square$ 있음

처음으로 담배를 한 두 모금이라도 피워 본 때는 언제입니까? 만ㄴㅅㅅㅔ

최근 1 달 동안 담배를 한 대 라도 피운 날은 며칠입니까?

최근 1 달 동안 담배를 피운 적이 없음으 11 번 문항으로 넘어가십시오

) 최근 1 달 동안 담배를 피운 날, 하루 평균 몇 개비나 피웠습니까?

개비

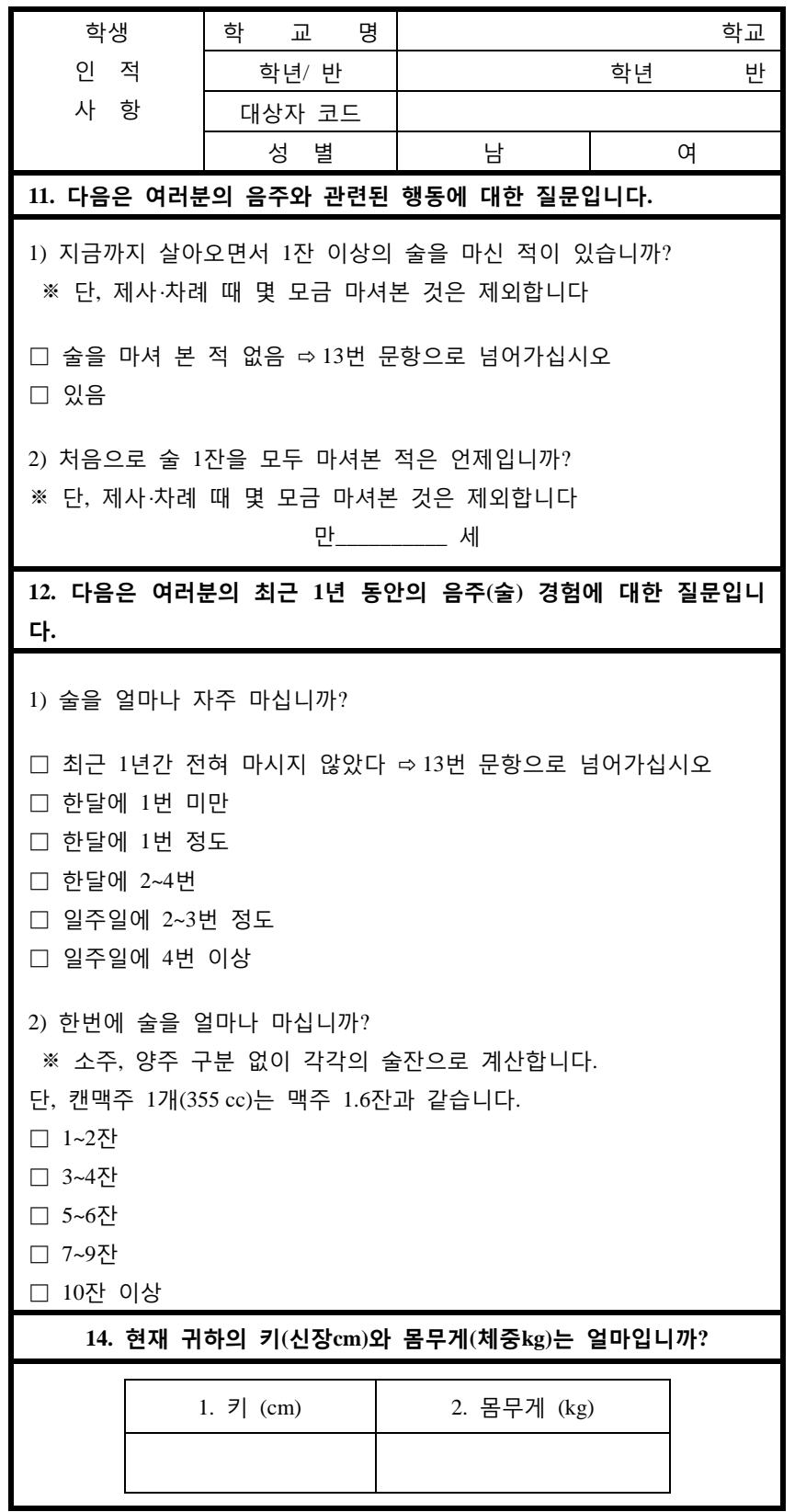




\begin{tabular}{|c|c|c|c|c|c|}
\hline \multicolumn{6}{|c|}{ 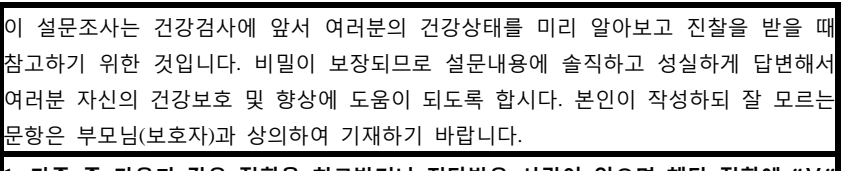 } \\
\hline \multicolumn{6}{|c|}{$\begin{array}{l}\text { 1. 가족 중 다음과 같은 질환을 치료받거나 진단받은 사람이 있으면 해당 질환에 "V" } \\
\text { 표시를 하여 주십시오. }\end{array}$} \\
\hline \multicolumn{2}{|c|}{ 가족의 의학적 병력 } & 있음 & 누가 & & 질병명 \\
\hline \multicolumn{6}{|c|}{ 고혈압이나 뇌졸증(중풍) } \\
\hline \multicolumn{6}{|c|}{ 협심증.심근경색.심부전 등 심장질환 } \\
\hline \multicolumn{6}{|c|}{ 당뇨병 } \\
\hline \multicolumn{6}{|l|}{ 암 } \\
\hline \multicolumn{6}{|l|}{ 간질환 } \\
\hline \multicolumn{6}{|l|}{ 결핵 } \\
\hline \multicolumn{6}{|c|}{ 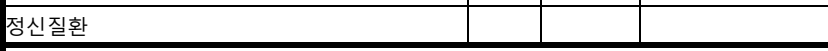 } \\
\hline \multicolumn{6}{|c|}{$\begin{array}{l}\text { 2. 최근 } 1 \text { 년 동안 다음과 같은 질병을 않은 적이 있으면 모두 "질병명을 써 주십시오.시를 하고 구 } \\
\end{array}$} \\
\hline \multicolumn{4}{|c|}{\begin{tabular}{|c|} 
질병의 과거력 \\
\end{tabular}} & & 질병명 \\
\hline \multirow{3}{*}{ 소화기계 } & \multicolumn{3}{|l|}{ 위염 또는 소화성궤양 } & & \\
\hline & \multicolumn{3}{|l|}{ 변비 } & & \\
\hline & \multicolumn{3}{|l|}{ 장염 } & & \\
\hline \multirow{4}{*}{ 호흡기계 } & \multicolumn{3}{|l|}{ 천식 } & & \\
\hline & \multicolumn{3}{|c|}{ 축농증 } & & \\
\hline & \multicolumn{3}{|c|}{ 알레르기성비염 또는 만성비염 } & & \\
\hline & \multicolumn{3}{|c|}{ 편도선비대 } & & \\
\hline \multirow{2}{*}{ 눈 } & \multicolumn{3}{|l|}{ 안질환.사시 등 } & & \\
\hline & \multicolumn{3}{|l|}{ 중이염 } & & \\
\hline \multirow{2}{*}{ 귀 } & \multicolumn{3}{|l|}{ 청력장애 } & & \\
\hline & 그 밖의 귀 질환(이명 등) & & & & \\
\hline 피부 & 아토피피부병 & & & & \\
\hline & 그 밖의 피부질환 & & & & \\
\hline 순환기계 & 빈혈 & & & & \\
\hline & 고혈압 & & & & \\
\hline & 척추측만증 & & & & \\
\hline 그고격계 & 디스크나 요통 & & & & \\
\hline 는록계 & 사지운동의 장애 & & & & \\
\hline & 외상이나 사고 & & & & \\
\hline & 소아정신과 질환 & & & & \\
\hline & 결핵 & & & & \\
\hline & 약물알레르기 & & & & \\
\hline & 당뇨병 & & & & \\
\hline & 두통(편두통 제외) & & & & \\
\hline $\begin{array}{l}\text { 글 밖화의 } \\
\text { 봥 }\end{array}$ & 경련이나 발작(경기) & & & & \\
\hline 실완 능 & 언어장애(말더듬 포함) & & & & \\
\hline & 간염 (어려서부터) & & & & \\
\hline & 수술한 경험(어려서부터) & & & & \\
\hline & 입원한 경험(어려서부터) & & & & \\
\hline
\end{tabular}

\section{문 진 표 \\ (중·고등학생용)}

\section{3. 최근 한 달간 경혐한 증상에 모두 "V"표시를 하여 주십시오.}

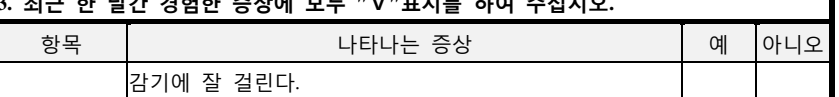

전신 상태 온 몸에 힘이 없고 쉽게 피로하다.

건강하지 않다고 생각한다.

재채기와 함께 코와 눈이 가렵고 맑은 콧물이 흐를 때가

있다.

숨쉴 때 숨이 가쁘면서 가슴에서 쌕쌕하는 소리나 휘파

람 소리가 들릴 때가 많다.

호흡기 기침과 함께 누런 가래가 올라온다.

평소 코로 숨쉬기가 불편하고 코가 막힌다.

코를 심하게 곤다는 말을 듣는다.

열이 많이 나면서 목이 따가울 때가 자주 있다.

목에서 몽우리가 만져진다.

순환기 $\quad$ 운동을 조금만 해도 다른 사람보다 숨이 심하게 차다.

혈색이 안 좋고 가만히 있어도 심장이 두근거린다.

속이 쓰리거나 아플 때가 있다.

\begin{tabular}{l|l}
\multirow{3}{*}{ 소화기 } & 속이 답답하거나 가득 찬 듯한 느낌이 있다 \\
\cline { 2 - 3 } & 아랫배가 살살 아프거나 설사를 자주 한다. \\
\cline { 2 - 3 } &
\end{tabular}

배가 팽팽하거나 가스가 찬 것 같다.

기분이 처지거나 우울해서 희망이 없다는 느낌이 든다.

학교를 가고 싶지 않을 때가 자주 있다

정신 건감 자살을 심각하게 생각하거나 자살을 시도한 적이 있다.

미칠 것 같은 불안을 자주 느낀다.

차분하지 않고 지나치게 활동적이라 다른 아이에게 방헤 가 되는 경우가 있다.

혈액 코피가 자주 나고 다치면 피가 잘 멈추지 않는다. 몸에 멍이 잘 든다.

두통이나 편두통이 심하다.

귓속이 아프거나 귀에서 분비물이 나온다.

바의 증상ㄱㅇ에서 매미우는 소리나 윙하는 소리가 들린다.

턱관절이 아프거나 입이 잘 벌어지지 않는다.

목.허리. 무릎 등이 쑤시거나 아프다. (여학생) 생리통이 심하다.

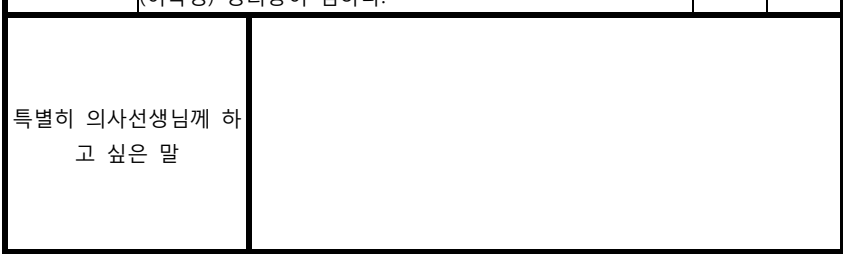

\begin{tabular}{|c|c|c|c|}
\hline \multirow{2}{*}{$\begin{array}{c}\text { 학생 } \\
\text { 인 적 } \\
\text { 사 항 }\end{array}$} & 학 교 명 & \multicolumn{2}{|c|}{ 학교 } \\
\cline { 2 - 4 } & 학년/ 반 & \multicolumn{2}{|c|}{ 학년 } \\
\cline { 2 - 4 } & 대상자 코드 & \multicolumn{2}{|c|}{} \\
\cline { 2 - 4 } & 성 별 & 남 & 여 \\
\hline
\end{tabular}

4. 다음은 여러분의 건강생활과 관련된 행동에 대한 질문입니다. 자신에게 해당되는 질 문에 "V"표시를 하여 주십시오.

\begin{tabular}{|c|c|c|c|}
\hline & 건 강 생 활 행 동 & 예 & 아니오 \\
\hline & 아침은 규칙적으로 먹는 편이다. & & \\
\hline & 매일 우유나 유제품을 먹는다. & & \\
\hline 시새화 & 매일 채소와 과일을 먹는다. & & \\
\hline ㄱㄱㄱㅇㅇㅇ활 & 단음식이나 짠 음식을 거의 먹지 않는다. & & \\
\hline & 청량음료.햄버거.피자 또는 과자를 거의 매일 먹는다. & & \\
\hline & 체중을 줄이기 위해 굶거나 약을 먹는다. & & \\
\hline 개인위생 & $\begin{array}{l}\text { 식사하기 전이나 외출 후 돌아와서 비누로 손을 } \\
\text { 씻는다. }\end{array}$ & & \\
\hline & 하루에 두 번 이상 이를 닦는다. & & \\
\hline 운동 & $\begin{array}{l}\text { 주 3회 이상 땀이 나거나 숨이 찰 정도로 운동을 } \\
\text { 하거나 일을 한다. }\end{array}$ & & \\
\hline & 공부와 운동을 잘 안배하여 자고 나면 개운하다. & & \\
\hline & 자동차를 탈 때 안전벨트를 맨다. & & \\
\hline 안전 & $\begin{array}{l}\text { 인라인스케이트, 롤러블레이드, 스케이트보드, } \\
\text { 자전거 등을 탈 때 헬멧이나 보호구를 착용한다. }\end{array}$ & & \\
\hline 이터네 & 인터넷이나 게임을 하루에 2 시간 이상 한다. & & \\
\hline 난더싯 & 음란물을 보거나 성인사이트에서 채팅을 자주 한다. & & \\
\hline & $\begin{array}{l}\text { 지난 1년 동안 친구들에게 괴롭힘이나 따돌림을 } \\
\text { 당한 적이 있다. }\end{array}$ & & \\
\hline & $\begin{array}{l}\text { 고민이 있거나 괴로울 때 의논할 수 있는 사람이 } \\
\text { 있다. }\end{array}$ & & \\
\hline & 가정(가족)내의 문제에 대해 걱정이 된다. & & \\
\hline 학교생활 & $\begin{array}{l}\text { 지난 1년 동안 가출하는 것을 심각하게 생각해 본 } \\
\text { 적이 있다. }\end{array}$ & & \\
\hline & $\begin{array}{l}\text { 가정이나 학교에서 폭력으로 인해 자신의 안전이 } \\
\text { 위협을 받고 있다. }\end{array}$ & & \\
\hline & $\begin{array}{l}\text { 무기로 사용할 목적으로 칼. 몽둥이.쌍절곤 등을 가지고 다 } \\
\text { 닌 적이 있다. }\end{array}$ & & \\
\hline & 지난 1 개월 동안 담배를 피운 적이 있다. & & \\
\hline ㅇㅑㅑ뭄 & 지난 1개월 동안 술을 마신 적이 있다. & & \\
\hline ᄀㄹㄹㄹ & $\begin{array}{l}\text { 환각을 목적으로 불법으로 대마초나 향정신성 약물을 사용 } \\
\text { 한 적이 있다. }\end{array}$ & & \\
\hline 서 & 성문제에 대해서 고민이 된다. & & \\
\hline 8 & 육체적.정신적.성적으로 학대를 당한 적이 있다. & & \\
\hline \% 고민이나 & 괴로온 일에 대해 상담을 받고 싶다. & & \\
\hline 학교 재량란) & & & \\
\hline
\end{tabular}


